\title{
Zonal Necrosis
}

National Cancer Institute

\section{Source}

National Cancer Institute. Zonal Necrosis. NCI Thesaurus. Code C96350.

A morphologic finding referring to the presence of necrosis that is confined to a specific anatomic zone. Representative example is the hepatic zonal necrosis that affects the hepatic parenchyma either in the portal areas or around the hepatic veins. 